\title{
HELICOBACTER PYLORI SEROPOSITIVITY AMONG CHILDREN IN DUHOK CITY, IRAQ
}

\author{
Nizar B. Yahya \\ Hevi Paediatric Teaching Hospital, Duhok, Kurdistan Region - Iraq - (nezar11@yahoo.com)
}

Received: Jul. 2018 / Accepted: Sept., 2018 / Published: Sept., 2018

https://doi.org/10.25271/sjuoz.2018.6.3.508

\begin{abstract}
:
Introduction: Helicobacter pylori (H. pylori) is a gram negative bacteria that causes gastritis and peptic ulcer disease (PUD). It is widely accepted that the infection may occur early in life and may persist for decades before causing diseases. The aim of this paper was to determine the prevalence of $H$. pylori seropositivity in pediatric age group and to examine the associated risk factors. Patients and methods: Blood samples were collected from 100 subjects attending Hevi Pediatric Teaching Hospital over a period of 6 months and IgG positivity was determined. A questionnaire sheet was prepared and used for each study subject. Data were collected by a face-to-face interview.Results: It was found that 28/100 (28\%) of the recruited sample was positive for $\mathrm{H}$. pylori seropositivity. A significant association was found between the number of siblings and $H$. pylori positivity $(\mathrm{P}=0.01, \mathrm{OR}=1.3)$. No significant relationships were found between other factors and $H$. pylori positivity. Conclusions: The prevalence of $H$. pylori infection was less than that reported in the city previously and less than that reported in neighboring countries. A significant positive association was found between number siblings and H. pylori infection rate. Further studies are needed recruiting larger sample size to explore $H$. pylori prevalence and its associated risk factors.
\end{abstract}

KEYWORDS: Helicobacter pylori, Pediatric, Children, Duhok, Iraq.

\section{INTRODUCTION}

Helicobacter pylori is a gram negative spiral-shaped bacillus bacteria which causes gastritis and peptic ulceration (Atherton, 2006). The eradication of such microorganism is pivotal in the treatment of peptic ulcer disease (PUD). Infection with this microorganism plays a major role in the pathogenesis of gastric adenocarcinoma (GA) (Hussein 2010; Wroblewski et al., 2010). GA is the second most important cause of cancer deaths worldwide (Atherton, 2006). It has been found that infection intermingles with environmental factors plus human genomic make up to develop cancer (Atherton, 2006) Hussein 2010; Wroblewski et al., 2010). Infection with $H$. pylori is very common and half of the world's population is estimated to be infected. The prevalence of infection increases markedly with age, such an increase might be due to a birth-cohort effect (Atherton, 2006) . Studies from Latin America showed variation in the prevalence rate of $H$. pylori in children (Santos et al., 2009 ). While the highest infection rate was found in Argentina where $H$. pylori prevalence was $25 \%$, the highest infection rate was recorded in Bolivia (74\%) (Santos et al., 2009 ). Additionally, H. pylori infection rates were 25\%, 31\% and $82 \%$ in Israel, Turkey and Iran, respectively (Falsafi et al., 2005; Muhsen et al., 2006; Ozbey et al., 2015). In a previous study conducted in Iraq, the prevalence of $H$. pylori varied according to age ranging from $27 \%$ in children to $58 \%$ in teenagers (Hussein et al., 2008). In the same study, the infection rate was found to be $78 \%$ and was significantly higher than the prevalence in children (Hussein et al., 2008). Overcrowding, parent's education and bad hygiene have been reported as risk factors for infection in children (Santos et al., 2009 ). The role of breastfeeding is controversial. Results of some studies found breastfeeding as a risk factor due to intimate contact between the infant and its infected mother (Malaty et al., 1996; Dore et al., 2002; Fialho et al., 2010; Choi et al., 2016). No study has been conducted in Duhok city determining $H$. pylori infection associated risk factors. Therefore this study was conducted to investigate the prevalence of $H$. pylori in children and to determine the risk factors associated with the infection.

\section{PATIENTS AND METHODS}

\subsection{Blood samples}

Blood samples were collected from 100 subjects attending Hevi Pediatric Teaching Hospital over a period of 6 months from November, 2017 to April, 2018. Five $\mathrm{mL}$ of blood was taken from each subject using $5 \mathrm{~mL}$ syringe and needle. Blood samples were centrifuged at $1500 \mathrm{rpm}$ for $3 \mathrm{~min}$ to obtain serum samples that were kept frozen in $-20^{\circ} \mathrm{C}$ until the test was performed. Anti- H. pylori $\mathrm{IgG}$ positivity was determined using commercial kit (AMP, Bucharest, Romania) and following manufacturer's instruction. All patients who attended nutrition clinic and whom their guardians agreed were included in this study. Only patients who their parents disagreed to participate were excluded.

\subsection{Questionnaire}

A questionnaire sheet was prepared and used to collect personal information by a face-to-face interview for each study subject. The questionnaire covered age, sex, residency, body mass index (BMI), number of siblings, education status of parents, and history of feeding type.

\subsection{Ethics}

The study was approved by the scientific and ethics committees of Hevi pediatrics hospital and the college of medicine, University of Duhok. Written consent was obtained from guardians of recruited subjects.

\subsection{Statistics}

Chi-squared test was applied to assess associations between $H$. pylori positivity and categorical variables. Linear regression 
analysis test was used to compare continues data. $\mathrm{P}$ value of 0.05 or less was regarded significant. All computations were carried out using SPSS version 21.

\section{RESULTS}

\subsection{Patients' characteristics and H. pylori prevalence}

During the period of study between the first of November 2017 to the $30^{\text {th }}$ of April 2018, 100 patients with the age average of $5.9 \pm 5$ years were recruited. $47 / 100(47 \%)$ of the recruited subjects were male and 72/100 (72\%) were from rural area. $39 / 100(39 \%)$ of recruited children gave a history of exclusive breastfeeding during the first 6 months of life. $48 / 100(48 \%)$ of the mothers and $38 \%$ of the fathers claimed that they never entered school. Results for anti-HP IgG showed that 28/100 $(28 \%)$ of the recruited sample was positive for $H$. pylori seropositivity.

\section{2 $\mathrm{H}$. pylori infection risk factors}

The association between $H$. pylori positivity and different variables were studied. No association was found between types of feeding and $H$. pylori positivity ( $\mathrm{P}>0.05$ for all). Additionally, no associations were found between education levels of the parents and $H$. pylori positivity ( $\mathrm{P}>0.05$ for all). A significant association was found between the number of siblings and $H$. pylori positivity $(\mathrm{P}=0.01, \mathrm{OR}=1.3)$. Finally, no significant relationships were found between age, gender, residency or BMI and $H$. pylori positivity (table 1 ).

Table 1 . The association between $H$. pylori positivity and different variables

\begin{tabular}{|c|c|c|c|}
\hline Variables & $\begin{array}{l}\text { H. pylori } \\
\text { positive }\end{array}$ & $\begin{array}{l}H . \quad \text { pylori } \\
\text { negative }\end{array}$ & $P$ value \\
\hline \multicolumn{4}{|c|}{ Feeding } \\
\hline Breastfeeding & $11(28.2 \%)$ & $28(71.8 \%)$ & \multirow{3}{*}{0.9} \\
\hline Formula & $8(29.6 \%)$ & $19(70.4 \%)$ & \\
\hline Mixed & $9(26.5 \%)$ & $25(73.5 \%)$ & \\
\hline \multicolumn{4}{|c|}{ Mother Education } \\
\hline Illiterate & $17(35.4 \%)$ & $31(64.6 \%)$ & \multirow{3}{*}{0.22} \\
\hline $\begin{array}{l}\text { Secondary } \\
\text { school }\end{array}$ & $9(19.6 \%)$ & $37(80.4 \%)$ & \\
\hline Higher education & $2(33.3 \%)$ & $4(66.7 \%)$ & \\
\hline \multicolumn{4}{|c|}{ Father Education } \\
\hline Illiterate & $11(28.9 \%)$ & $28(71.8 \%)$ & \multirow{3}{*}{0.79} \\
\hline $\begin{array}{l}\text { Secondary } \\
\text { school }\end{array}$ & $15(30 \%)$ & $35(70 \%)$ & \\
\hline Higher education & $2(18.2 \%)$ & $9(81.8 \%)$ & \\
\hline BMI & 17.63 & 14.2 & 0.7 \\
\hline Age & $\begin{array}{l}12 \text { months } \\
-15 \text { years }\end{array}$ & $\begin{array}{l}11 \text { months }-9 \\
\text { years }\end{array}$ & 0.1 \\
\hline $\begin{array}{l}\text { Number of } \\
\text { sibling }\end{array}$ & $3-7$ & $1-5$ & 0.01 \\
\hline Rural & 23 & 41 & 0.9 \\
\hline
\end{tabular}

\section{DISCUSSION}

Infection with $H$. pylori is one of the most common chronic infections worldwide and it has been estimated that around $50 \%$ of world's population is infected with this microorganism (Hussein 2010; Wroblewski et al., 2010). Persistent infection with $H$. pylori causes peptic ulcer diseases and plays an important role in the pathogenesis of gastric adenocarcinoma. Three factors interplay roles in disease development process: $H$. pylori virulence factors, immune response and environmental factors (Hussein 2010; Wroblewski et al., 2010). It is widely accepted that the infection may occur early in life and may persist for decades before causing diseases. $H$. pylori infection was studied thoroughly in Iraq (Hussein et al., 2008; Hussein et al., 2008; Hussein et al., 2016). Additionally, the prevalence of the infection was studied in different age groups (Hussein et al., 2008). However, no study has been conducted to determine the risk factors associated with the infection. Thus, this study investigated the prevalence of the infection and its risk factors. In this study, the prevalence of infection in the recruited subjects was found to be $28 \%$ which is less than what was found previously in the same city $(10 \%)$ (Hussein et al., 2008). The decrease in the infection rates might be due to the improvement of life standards and hygiene in the region. Furthermore, the prevalence in our study was much lower than that found in Iran where H. pylori infection rates were found to be $47 \%-64 \%$ (Falsafi et al., 2005). In Saudi Arabia, another neighboring country to Iraq, recruiting similar study that recruited 303 children showed that the prevalence rate was found to be around 50\% (Hasosah et al., 2015). In the other hand, the infection rate in our city was higher than that found in the majority of developing countries where around $10 \%$ of the pediatric population was shown to be infected with H. pylori (Hussein et al., 2008).

Different risk factors are associated with $H$. pylori infection during childhood. The role of breastfeeding is controversial in the transmission of H. pylori (Dore et al., 2013). While some reports showed a relationship between breastfeeding and the infection, others found a protective role for breastfeeding preventing the infection (Dore et al., 2013). In our study, we classified our patients into three groups: exclusive breastfeeding; mixed feeding or artificial milk feeding. No relationship was found between the type of feeding and $H$. pylori infection. In a study conducted in Brazil, it was found that the number of siblings played a substantial role in acquiring $H$. pylori infection during childhood (Fialho et al., 2010) . Same results were found in Japan (Osaki et al., 2005) and in agreement with this, a significant correlation between the number of siblings and $H$. pylori infection was found. In a meta-analysis conducted by de Martel and colleague, $H$. pylori was found more predominantly in male. Such relationship was not detected in our study. In addition, no correlation was found between age and $H$. pylori positivity in this study. A previous study conducted in Russia, a strong relationship between mother's education level and $H$. pylori infection rate was found (Malaty et al., 2015). In a study conducted in Taiwan, the lower education levels of mothers were associated with higher infection rates (Wu et al., 2015). In contrast to this, no relationship was found between education level and $H$. pylori infection in our study. This might be explained partly by the small sample that was used in our study. Further studies are needed recruiting a large sample size to explore this area. The role of $H$. pylori infection in obesity is under investigation. While $H$. pylori was associated in several studies, no relationship was found between $H$. pylori and increased BMI (Ioannou et al., 2005; Marcela et al., 2007; Arslan et al., 2009). On the other hands, several studies showed an increase in BMI after H. pylori eradication (Ioannou et al., 2005; Choi et al., 2016). In our study, no relationship was found between BML levels and $H$. pylori positivity. This might be due to the small sample size recruited in this study. Further studies are needed to explore the effect of $H$. pylori eradication on BMI levels. To conclude, the prevalence of $H$. pylori infection was found in $28 \%$ of the recruited children. This was less than that reported in the city previously and less than that reported in neighboring countries. A significant positive association was found between number of siblings and $H$. pylori infection rate. 
No association was found between parent's education, gender, age or BMI and H. pylori positivity. Further studies are needed recruiting larger sample size to explore $H$. pylori prevalence and its associated risk factors.

\section{REFERENCES}

Arslan, E., H. Atligan and A. Yavasoglu (2009). "The prevalence of Helicobacter pylori in obese subjects." European Journal of Internal Medicine 20(7): 695697.10.1016/j.ejim.2009.07.013: 10.1016/j.ejim.2009.07.013

Atherton, J. C. (2006). "THE PATHOGENESIS OF HELICOBACTER PYLORI INDUCED GASTRODUODENAL DISEASES." Annual Review of Pathology: Mechanisms of Disease 1(1): 6396.10.1146/annurev.pathol.1.110304.100125: 10.1146/annurev.pathol.1.110304.100125

Choi, J. S., K. O. Ko, J. W. Lim, E. J. Cheon, G. M. Lee and J. M. Yoon (2016). "The Association between Helicobacter pylori Infection and Body Weight among Children." Pediatric Gastroenterology, Hepatology \& Nutrition 19(2): 110115.10.5223/pghn.2016.19.2.110: 10.5223/pghn.2016.19.2.110

Dore, M. P., H. M. Malaty, D. Y. Graham, G. Fanciulli, G. Delitala and G. Realdi (2002). "Risk Factors Associated with Helicobacter pylori Infection among Children in a Defined Geographic Area." Clinical Infectious Diseases 35(3): 240245

Falsafi, T., N. Valizadeh, S. Sepehr and M. Najafi (2005). "Application of a Stool Antigen Test To Evaluate the Incidence of Helicobacter pylori Infection in Children and Adolescents from Tehran, Iran." Clinical and Diagnostic Laboratory Immunology 12(9): 1094-1097.10.1128/cdli.12.9.10941097.2005: 10.1128/cdli.12.9.1094-1097.2005

Fialho, A. M. N., A. B. C. Braga, M. B. Braga Neto, J. G. Carneiro, A. M. C. Rocha, M. N. Rodrigues, D. M. M. Queiroz and L. L. B. C. Braga (2010). "Younger Siblings Play a Major Role in Helicobacter pylori Transmission Among Children From a Low-Income Community in the Northeast of Brazil." Helicobacter 15(6): 491-496.10.1111/j.15235378.2010.00791.x: 10.1111/j.1523-5378.2010.00791.x

Hasosah, M., M. Satti, A. Shehzad, A. Alsahafi, G. Sukkar, A. Alzaben, A. Sunaid, A. Ahmed, S. AlThubiti, A. Mufti and K. Jacobson (2015). "Prevalence and Risk Factors of Helicobacter pylori Infection in Saudi Children: A ThreeYear Prospective Controlled Study." Helicobacter 20(1): 56-63.10.1111/hel.12172: 10.1111/hel.12172

Hussein Nawfal, R., K. Robinson and C. Atherton John (2008). "A study of Age Specific Helicobacter pylori Seropositivity Rates in Iraq." Helicobacter 13(4): 306307.10.1111/j.1523-5378.2008.00618.x: 10.1111/j.15235378.2008.00618.x

Hussein, N. R. (2010). "Helicobacter pylori and gastric cancer in the Middle East: A new enigma?" World Journal of Gastroenterology: WJG 16(26): 32263234.10.3748/wjg.v16.i26.3226: 10.3748/wjg.v16.i26.3226

Hussein, N. R., M. Mohammadi, Y. Talebkhan, M. Doraghi, D. P. Letley, M. K. Muhammad, R. H. Argent and J. C. Atherton (2008). "Differences in Virulence Markers between Helicobacter pylori Strains from Iraq and Those from Iran: Potential Importance of Regional Differences in H. pyloriAssociated Disease." Journal of Clinical Microbiology
46(5):

10.1128/jcm.01737-07

1774-1779.10.1128/jcm.01737-07:

Hussein, N. R., Z. S. M. Saleem, A. A. Balatay, K. H. Abd, S. Daniel, A. A. Taha, N. M. R. Ibrahim and M. S. Assafi (2016). "Seroprevalence of Helicobacter pylori Infection in Renal Transplant Recipient Attending Duhok Kidney Disease Center." Transplantation Proceedings 48(1): $92-$ 95.10.1016/j.transproceed.2016.01.006: 10.1016/j.transproceed.2016.01.006

Ioannou, G. N., N. S. Weiss and D. J. Kearney (2005). "Is Helicobacter pylori seropositivity related to body mass index in the United States?" Alimentary Pharmacology \& Therapeutics 21(6): $\quad 765-772.10 .1111 / \mathrm{j} .1365-2036.2005 .02369 . \mathrm{x}$ : 10.1111/j.1365-2036.2005.02369.x

Malaty, H. M., V. Paykov, O. Bykova, A. Ross, D. P. Graham, J. F. Anneger and D. Y. Graham (1996). "Helicobacter pylori and Socioeconomic Factors in Russia." Helicobacter 1(2): 82-87.10.1111/j.1523-5378.1996.tb00015.x: 10.1111/j.1523-5378.1996.tb00015.x

Marcela, K., J. Bure $\AA_{i}$, I. Koupil, S. Rejchrt, V. Viktor, B. Seifert, O. i. Pozler, P. $\AA^{1 / 2 i v n} \tilde{A}^{1} \frac{1}{2}$, T. A. Douda, V. Palicka, J. Holcik and G. the European Society for Primary Care (2007). "Body indices and basic vital signs in Helicobacter pylori positive and negative persons." European Journal of Epidemiology 22(1): 67-75.10.1007/s10654-006-9090-1: 10.1007/s10654-006-9090-1

Muhsen, K. H., A. Athamna, M. Athamna, A. Spungin-Bialik and D. Cohen (2006). "Prevalence and risk factors of Helicobacter pylori infection among healthy 3- to 5-year-old Israeli Arab children." Epidemiology and Infection 134(5): 990996.10.1017/s0950268806006030: $10.1017 / \mathrm{s} 0950268806006030$

Osaki, T., M. Konno, H. Yonezawa, F. Hojo, C. Zaman, M. Takahashi, S. Fujiwara and S. Kamiya (2015). "Analysis of intrafamilial transmission of Helicobacter pylori in Japanese families." Journal of Medical Microbiology 64(1): $67-$ 73.doi:10.1099/jmm.0.080507-0: doi:10.1099/jmm.0.080507-0

Ozbey, G., Y. Dogan, K. Demiroren and I. H. Ozercan (2015) "Prevalence of Helicobacter pylori in children in eastern Turkey and molecular typing of isolates." Brazilian Journal of Microbiology 46(2): 505-511.10.1590/s1517838246220140234: 10.1590/s1517-838246220140234

Santos, I. S., J. Boccio, L. Davidsson, M. Hernandez-Triana, E. Huanca-Sardinas, M. Janjetic, S. Y. Moya-Camarena, M. C. Paez-Valery, V. Ruiz-Alvarez, M. E. Valencia, N. C. J. Valle, G. Vargas-Pinto, L. Solano and J. Thomas (2009). "Helicobacter pylori is not associated with anaemia in Latin America: results from Argentina, Brazil, Bolivia, Cuba, Mexico and Venezuela." Public Health Nutrition 12(10): 1862-1870.Doi: 10.1017/s1368980009004789: Doi: $10.1017 / \mathrm{s} 1368980009004789$

Soltani, J., J. Amirzadeh, S. Nahedi and S. Shahsavari (2013). "Prevalence of Helicobacter Pylori Infection in Children, a Population-Based Cross-Sectional Study in West Iran." Iranian Journal of Pediatrics 23(1): 13-18

Wroblewski, L. E., R. M. Peek and K. T. Wilson (2010). "Helicobacter pylori and Gastric Cancer: Factors That Modulate Disease Risk." Clinical Microbiology Reviews 23(4): 713 739.10.1128/cmr.00011-10: 10.1128/cmr.00011-10

Wu, M.-C., C.-H. Sung, Y.-C. Chang, C.-L. Ho, C.-C. Wu, K.-H. Wu, C.-Y. Lee and K.-D. Yang (2015). "Seroprevalence of Helicobacter pylori and Hepatitis A Virus among Children in Rural Central Taiwan." Japanese Journal of Infectious Diseases 68(6): 494-503.10.7883/yoken.JJID.2014.321: 10.7883/yoken.JJID.2014.321 